\title{
MicroRNAs transported by exosomes in body fluids as mediators of intercellular communication in cancer
}

This article was published in the following Dove Press journal:

OncoTargets and Therapy

21 July 2014

Number of times this article has been viewed

Iván Salido-Guadarrama'

Sandra Romero-Cordoba'

Oscar Peralta-Zaragoza ${ }^{2}$

Alfredo Hidalgo-Miranda'

Mauricio Rodríguez-

Dorantes'

'Oncogenomics Laboratory, National Institute of Genomics Medicine, Mexico City, Mexico; ${ }^{2}$ Direction of Chronic Infections and Cancer, Research Center in Infectious Diseases, National Institute of Public Health, Cuernavaca, Morelos, Mexico

Correspondence: Mauricio RodríguezDorantes

National Institute of Genomics Medicine, Periferico Sur No 4809, Col Arenal Tepepan, Mexico City 14610, Mexico Email mrodriguez@inmegen.gob.mx

\begin{abstract}
Cancer-cell communication is an important and complex process, achieved through a diversity of mechanisms that allows tumor cells to mold and influence their environment. In recent years, evidence has accumulated indicating that cells communicate via the release and delivery of microRNAs (miRNAs) packed into tumor-released (TR) exosomes. Understanding the role and mode of action of miRNAs from TR exosomes is of paramount importance in the field of cancer biomarker discovery and for the development of new biomedical applications for cancer therapeutics. In this review, we focus on miRNAs secreted via TR exosomes, which by acting in a paracrine or endocrine manner, facilitate a diversity of signaling mechanisms between cancer cells. We address their contribution as signaling molecules, to the establishment, maintenance, and enhancement of the tumor microenvironment and the metastatic niche in cancer. Finally, we address the potential role of these molecules as biomarkers in cancer diagnosis and prognosis and their impact as a biomedical tool in cancer therapeutics.
\end{abstract}

Keywords: tumor cells, multivesicular bodies, interference RNA, biomarkers and therapeutics

\section{Cellular communication in the cancer environment}

Living organisms depend on receiving and processing information for their survival. Information can be received from the environment in the form of physical or chemical stimuli (ie, variation in temperature and availability of nutrients) that give rise to a variety of responses. ${ }^{1}$ The nature of the response elicited depends on both the nature of the signal transmitted and the type of cell that receives that signal. In eukaryotic organisms, a cell can communicate with itself or with other cells. Intercellular communication allows a population of cells to coordinate and execute biological functions and perform specialized tasks, which could not be accomplished otherwise. For example, the process of morphogenesis is controlled by a group of cells that establishes proper connections with each other. ${ }^{1,2}$

The information exchanged between cells may involve direct cell-to-cell contact (ie, juxtacrine interaction and gap junctions) or the release of soluble mediators which can act over a short distance (autocrine and paracrine mechanisms ${ }^{3}$ ) or travel long distances, circulating in blood and body fluids to elicit a response in cells located in tissues at distant organs, ${ }^{4}$ in an endocrine fashion. Intercellular communications operate by means of molecular messengers such as proteins, small peptides, lipids, carbohydrates, and nucleic acids. These molecules are released in the extracellular space to bind to receptors on other cells, thus modifying intracellular signaling in the recipient cells. Following the receptor binding on the target cell, the information 
is translated into an intracellular signal, which produces a specific behavior in individual cells and in tissues. There is growing evidence that intercellular communication through molecular signals is not a random process. ${ }^{5,6}$ In fact, the release of such signals is a tightly regulated process that can involve the production and secretion of a variety of supramolecular structures, including nanotube structures and membranous vesicles (MVs). ${ }^{7,8}$ Of particular interest, MVs are complex and dynamic membranous compartments known to act as mediators of intercellular communications due to their capacity to transmit a collection of proteins, lipids, or nucleic acids, including DNA, messenger (m)RNA, and microRNAs (miRNAs), to different recipient cells. ${ }^{8,9}$ Once they are released, MVs can either target a neighboring cell or reach a cell located at distant organs after entering the blood stream. The exact mechanisms by which target cells take up and integrate material carried by MVs are poorly understood. This transfer of material is a highly specific process that depends on the type and status of the donor and recipient cells and has different functional consequences. This mechanism of cell-to-cell behavioral regulation is particularly important in cancer. ${ }^{2}$ Through a shedding mechanism, tumor cells are capable of constitutively secreting a variety of MVs, which can potentially exert a paracrine influence on the surrounding cells to promote proliferation, ${ }^{10,11}$ stromal remodeling, ${ }^{12}$ angiogenesis, ${ }^{13,14}$ and immune evasion ${ }^{15,16}$ and invasion ${ }^{11,17,18}$ of tumor cells and also act in an endocrine way, interacting and releasing their cargo at cells located at distant organs, which could have profound effect on metastasis..$^{17,19,20}$

\section{Exosomes serve as signal transporters}

In 1981, Trams et $\mathrm{al}^{21}$ observed that cultures from various normal and neoplastic cell lines shed vesicles with 5 '-nucleotidase activity, suggesting that vesicles are derived from specific subdomains of the plasma membrane. Later on, shedding of a particular class of MVs from live cells was proposed to be a mechanism by which cells discard inert debris. ${ }^{22}$ Johnstone $^{23}$ and Harding et $\mathrm{al}^{22}$ introduced the term exosomes to refer to this class of MVs, which were involved in the removal of spent transferrin receptors from differentiating reticulocytes. The classification of an MV as an exosome is based primarily on size, density, and membrane composition. ${ }^{24}$

Exosomes are membrane vesicles that have the same topology as the cell and are approximately 30-100 nm in diameter, $9,25,26$ though larger exosomes have also been reported..$^{27,28}$ Exosomes are vesicles of endocytic origin that are released by most cell types when multivesicular bodies (MVBs) fuse with the plasma membrane. ${ }^{29,30}$ As mentioned above, the intercellular exchange of protein, DNA, and RNA via exosomes is a potential mechanism of cell-to-cell communication within the tumor microenvironment. Information regarding exosome content is summarized in Exocarta (http://www.exocarta.org). ${ }^{25}$ Moreover, profiling studies have revealed that exosomes of different cellular origin contain a unique expression profile of mRNAs and miRNAs, which may also differ from the signatures of their parent cells. ${ }^{31-33}$

The mechanisms underlying how exosomes interact with the recipient cells have not yet been clarified. Some studies have demonstrated that exosomes can fuse with the plasma membrane of the target cells, which leads to the release of exosome content into the target cell. ${ }^{33,34}$ Although exosomes have been best characterized in cells of the immune system, ${ }^{2,35}$ there is evidence that these vesicles are secreted by many, if not most, cell types, and it is clear that they can interact with other cells to evoke paracrine or endocrine responses in these recipient cells.

In particular, miRNAs, natural effector molecules of RNA interference, ${ }^{36-38}$ which are already implicated in cancer development, also play an important role as distant modulators via tumor-released (TR) exosome signaling pathways.

\section{Exosomes are naturally engineered for the selective loading of miRNAs}

The biogenesis, release, and uptake of exosomes are tightly regulated processes governed by diverse signaling mechanisms, which can be altered in pathologies such as cancer to create dysfunctional pathways. Generally, exosome biogenesis, ${ }^{9,31}$ material cargo sorting, ${ }^{9,39}$ and release ${ }^{40}$ involve the endosomal sorting complex required for transport (ESCRT complex), acting together with associated proteins. The ESCRT complex recognizes ubiquitinated membrane proteins and promotes their internalization into the MVB. ${ }^{41}$ The presence of late endosome components like Alix, (tumor susceptibility gene 101) TSG101, and tetraspanins reveals the MVB origin of exosomes. ${ }^{24,42}$ During the endosome formation process, material from the cell cytoplasm including RNA, protein, and DNA is sorted into exosomes..$^{29,30}$ The mechanism by which miRNAs package into exosomes remains elusive. Remarkably, there is growing evidence that the miRNA maturation process is linked to the formation and maturation of MVBs and exosomes.

Canonically, the biogenesis of miRNAs starts in the cell nucleus where DNA containing miRNAs is transcribed by RNA polymerase II to generate primary miRNAs 
(pri-miRNAs) ${ }^{43}$ The pri-miRNAs are processed by a microprocessor complex, consisting of the RNase type III endonuclease Drosha and an essential cofactor (DiGeorge syndrome critical region 8)/Pasha (protein containing two double-stranded RNA binding domains), to generate a precursor miRNA (pre-miRNA). ${ }^{44,45}$ Pre-miRNA is then exported to the cytoplasm by the exchange factor of the guanine Ran nucleotide (GTP-binding nuclear protein Ran) and the exportine- 5 receptor and is then processed by another RNase type III endonuclease known as Dicer, releasing 22-nucleotide miRNA duplex. One strand of the RNA duplex is selected to be subsequently loaded into the RNA-induced silencing complex (RISC) along with argonaut (AGO2) and GW182. ${ }^{46,47}$ In metazoans, miRNAs loaded into the RISC (miRISC) complex base pair with its target mRNA and induce translational repression and mRNA destabilization ${ }^{48-50}$ (Figure 1).

In 2009, two research groups demonstrated the association between GW182 and AGO2, both main components of the RISC and MVBs. ${ }^{51,52}$ Gibbings et $\mathrm{al}^{51}$ reported that predominantly GW182, but not AGO2, was enriched in the exosomes. Meanwhile, Lee et $\mathrm{al}^{52}$ showed that blocking the maturation of MVBs enhanced short interfering RNA (siRNA)- and miRNA-mediated silencing. This evidence suggests an important role for MVBs as a mechanism modulating the formation and the abundance of functional miRISC complex, thus, affecting its activity within the cell. Whether the incorporation of miRNAs into exosomes occurs at the pre-miRNA or mature miRNA level is not well understood. Recently, Villarroya-Beltri et $\mathrm{al}^{53}$ reported that mature miRNAs contain specific motifs that control their sorting in exosomes. In addition, they successfully revealed the identity of the trans-acting factor governing the loading of miRNAs into exosomes, the heterogeneous nuclear ribonucleoprotein A2B1 (hnRNPA2B1), which after being sumoylated, specifically binds exosomal miRNAs through the recognition of these motifs and controls their loading ${ }^{53}$ (Figure 1). Of relevance is the fact that some of the mechanism and pathways involved in exosome production, release, and uptake have been better studied in cancer cell models. In this regard, a recent study by Shen et $\mathrm{al}^{54}$ showed that epidermal growth factor receptor (EGFR), a known oncogene, impairs the miRNA maturation process under hypoxic conditions.

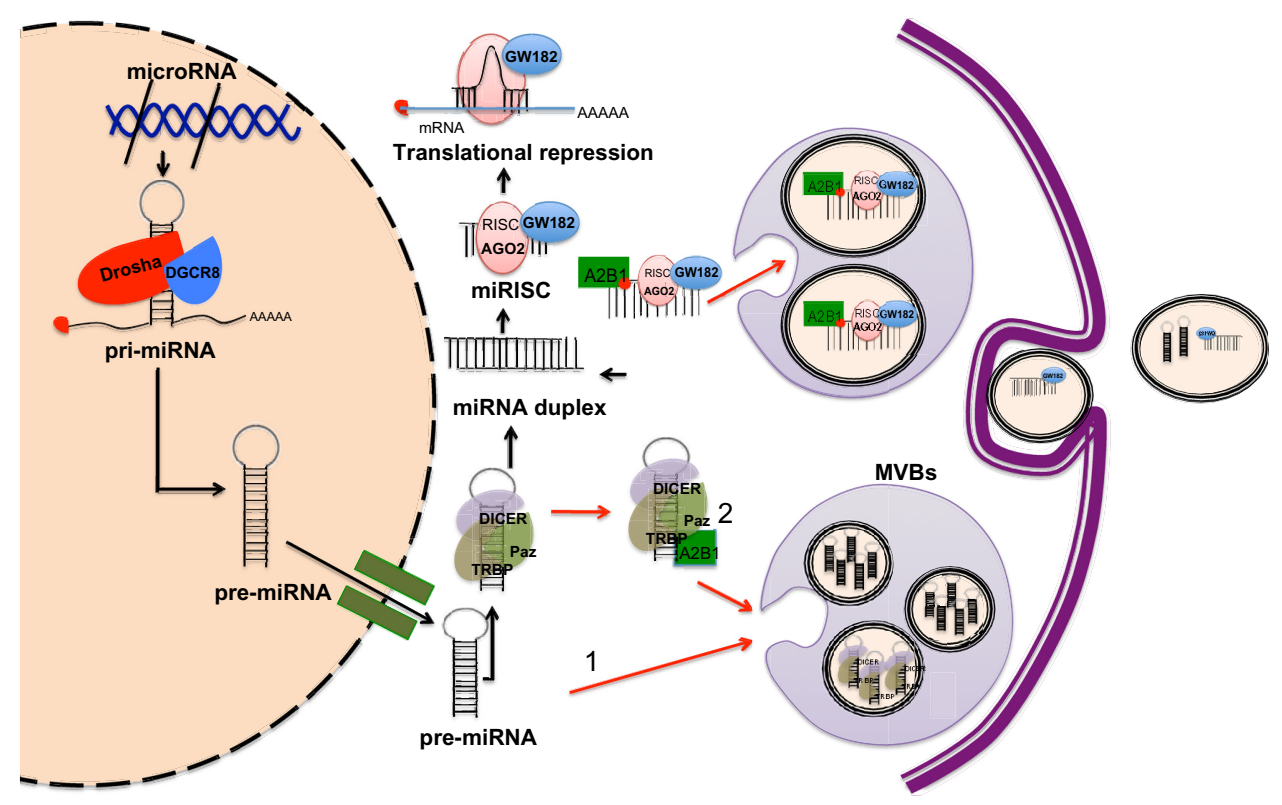

Figure I Model of miRISC complex formation, incorporation into MVBs and subsequent secretion in exosomes.

Notes: (A) MiRNAs coding genes are transcribed as pri-miRNAs in the nucleus. Next, pri-miRNAs are processed by the microprocessor complex, which is composed by Drosha and DiGeorge syndrome critical region 8 to generate pre-miRNAs. Pre-miRNAs are exported to the cytoplasm by an anti-port transporter called exportin-5. Once in the cytoplasm, the pre-miRNAs are excised by Dicer to generate an intermediary RNA duplex 22 nucleotides long. One strand of the RNA duplex is selected to be subsequently loaded into the RNA-induced silencing complex (RISC) along with argonaut (AGO2) and GWI82 to form mature RISC (miRISC) complex. MiRNAs in the miRISC can base pair with its target mRNA and induce translational repression and mRNA destabilization. If the miRISC does not interact with its target, it can then be selected and sorted into the MVBs, likely through a mechanism involving the protein hnRNPA2BI, which after being sumoylated, specifically binds miRNAs through the recognition of specific sequence motifs in the mature miRNA. Pre-miRNAs loaded into the RISC loading complex (pre-miRISC) may be sorted into MVBs (I). Sorting of premiRNAs into exosomes could also be occurring in a sequence-dependent manner (2); this, however, remains uncertain. Exosomes are derived from MVBs, also known as late endosomes. Exosomes containing miRISCs or pre-miRISCs are then secreted into the extracellular space. Black arrows indicate direction of canonic miRNA biogenesis and silencing action. Red arrows indicate direction of processes of miRNA maturation involving MVB production.

Abbreviations: hnRNPA2BI, heterogeneous nuclear ribonucleoprotein A2BI; miRNA, microRNA; miRISC, miRNAs loaded into the RISC; mRNA, messenger RNA; MVB, multivesicular body; pre-miRNA, precursor miRNA; pri-miRNA, primary miRNA; RISC, RNA-induced silencing complex; TRPB, TAR RNA binding protein. 
Strikingly, this novel intracellular function of EGFR occurs through its interaction with components of the RISC complex; therefore, internalization of EGFR could be imposing some type of regulation for the preferential incorporation of pre-miRNAs into MVBs. ${ }^{54}$ Nonetheless, the suggestion that pre-miRNAs are readily incorporated into exosomes and later processed to mature miRNAs would require the presence of members of the RISC-loading complex, namely Dicer or TRBP (TAR RNA binding protein), which to our knowledge has not been reported. What is certain is that diverse studies report that pre-miRNAs as well as mature miRNAs are released in exosomes. ${ }^{55-58}$

\section{Exosome miRNAs are messages involved in intercellular communication}

Our understanding of intercellular communication is mainly based on the secretion of soluble factors, such as growth factors and neurotransmitters, cytokines, and chemokines, and their specific recognition by cell-surface receptors. However, evidence indicating that cells also communicate via the direct exchange of DNA ${ }^{59-61}$ and $\mathrm{RNA}^{3,62}$ has been growing over the past several years. In 1988, Benner proposed that RNA is involved in cell-to-cell communication as a short-distance and fast-acting messenger. ${ }^{63}$ It has recently been reported that exosomes secreted by mast cell lines contain both mRNA and miRNA. ${ }^{3}$ Several studies have demonstrated that miRNAs are present in a cell-free form in human and mouse serum. ${ }^{34,64-66}$ These reports reinforced the idea that RNA could function in long-distance communication between cells. In fact, miRNAs have been found in various body fluids, including serum, plasma, saliva, tears, urine, amniotic fluid, colostrum, breast milk, bronchial lavage, cerebrospinal fluid, peritoneal fluid, pleural fluid, and seminal fluid. ${ }^{67}$ Despite increasing efforts, little is known about the mechanisms that explain the origin and stability of circulating miRNAs in those body fluids. ${ }^{4,68}$ It is known that miRNAs can be passively released from broken cells and apoptotic bodies ${ }^{68,69}$ and actively secreted as RNA-protein complexes. ${ }^{70,71}$ However, an advantage of exosomes as RNA delivery vehicles is that, unlike soluble factors, exosomes are protected from the environment by their lipid bilayer and are more likely to reach their target cells. ${ }^{35}$ In fact, exosomal miRNAs are more stable and resistant to degradation during prolonged storage and freeze-thaw cycles than cellular miRNAs. ${ }^{7,72,73}$ Another advantage is that exosomes can deliver multiple messages simultaneously, which

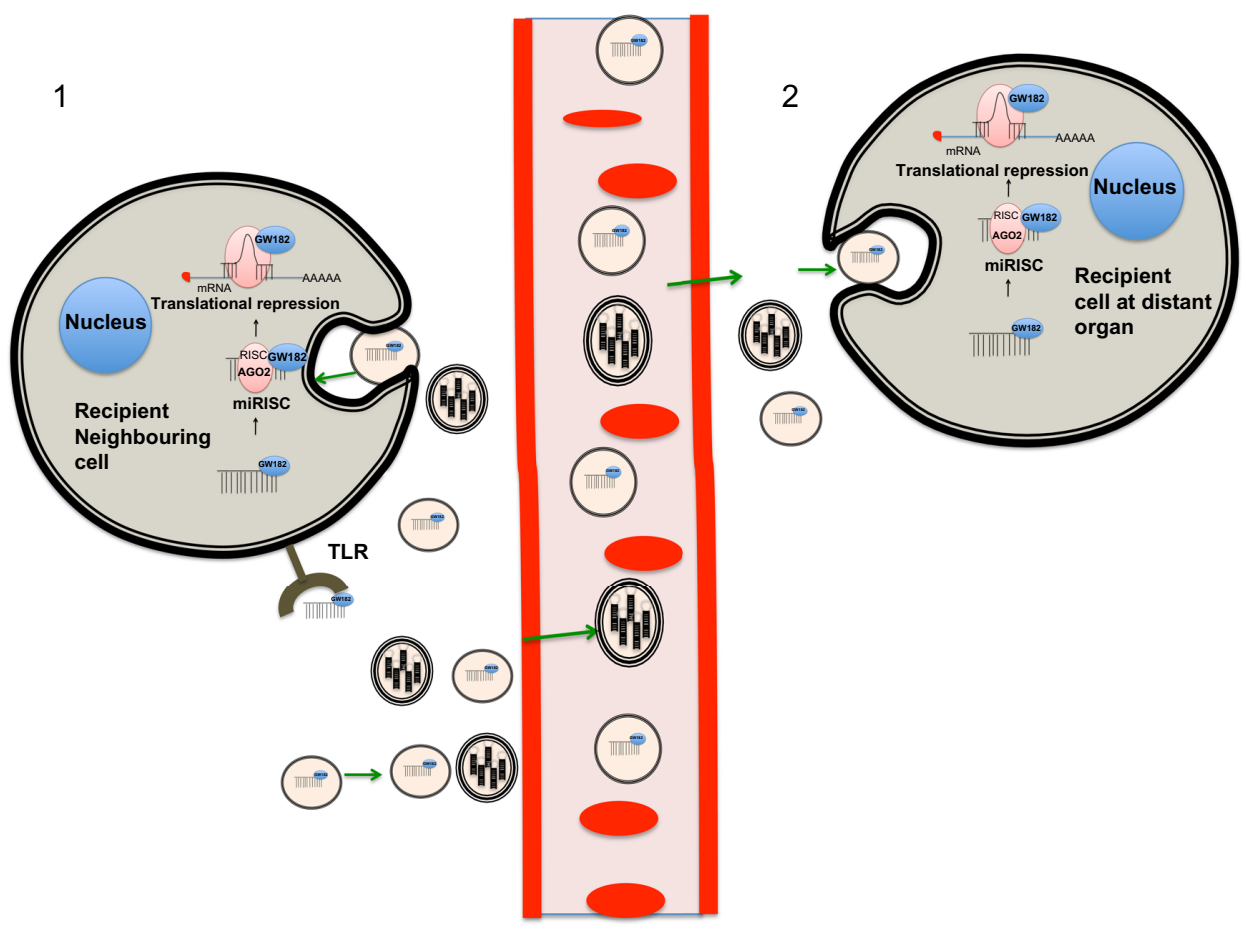

Figure 2 Biogenesis, packaging, secretion, and uptake of miRNA transported in exosomes.

Notes: Cancer cells can secrete exosomes, which act in different ways: (I) by acting in a paracrine fashion on recipient neighboring cells, into which miRNAs may carry out their canonical mechanism of post-transcriptional repression or may activate membrane surface receptors (ie, TLRs) to favor tumor growth and invasiveness; and (2) by exerting their function in an endocrine manner by entering the circulation and reaching tissues at distant organs, where they are taken up by recipient cells and condition the formation of a metastatic niche. Green arrows indicate direction of the exosome trafficking. Black arrows indicate direction of canonic miRNA silencing action.

Abbreviations: AGO2, argonaut; RISC, RNA-induced silencing complex; miRNA, microRNA; mRNA, messenger RNA; TLR, toll-like receptor. 
make them an attractive way of exchanging specific subsets of mRNA, miRNA, or proteins between donor and recipient cells, despite the distance between one and the other. There is increasing evidence that miRNAs are selectively packaged into exosomes. ${ }^{66,74-76}$ Therefore, exosomal transport of mRNAs and miRNAs from tumor cells to neighboring cells or cells located at distant organs could have a functional role in the process of tumorigenesis (Figure 2). ${ }^{62,77}$

\section{MiRNAs in exosomes from cancer cells: the Trojan horse}

One of the first pieces of evidence implicating miRNA transport by exosomes as a communication process among cancer cells came from Skog et al, ${ }^{33}$ who demonstrated that the messengers encoding for EGFRvIII protein and miR-21 are transported in glioblastoma-derived exosomes and that these molecules could be taken up by normal host cells and transformed into functional signals, stimulating proliferation of cancer cells. ${ }^{33}$ In a different study, Pegtel et al ${ }^{78}$ demonstrated that mature Epstein-Barr virus (EBV)-encoded miRNAs are secreted by EBV-infected B-cells through exosomes, and that these miRNAs accumulate in neighboring noninfected monocyte-derived dendritic cells (MoDCs). Furthermore, these EBV-miRNAs are functional because after internalization by MoDCs, investigators observed a dose-dependent miRNA-mediated repression of known EBV target genes, including $C X C L 11 / I T A C$, an immunoregulatory gene downregulated in primary EBV-associated lymphomas. ${ }^{78}$ This may represent some of the first evidence consistent with the idea that miRNAs delivered by exosomes can act as regulators of gene expression in distant cells. Ohshima et $\mathrm{al}^{74}$ found that the let-7 miRNA family was abundant in both the intracellular vesicles and exosomes from AZ-P7a cells, a metastatic gastric cancer cell line, while non-metastatic AZ-521, the parent cell line of AZ-P7a, showed no such high levels. This suggests that the exosomal mechanism may be used by tumor cells to launch out miRNAs, which predominately have tumor suppressive functions, preventing them from acting in their parent cell and thus maintaining its oncologic potential. However, whether their release is intended to promote or inhibit oncogenesis remains unclear. ${ }^{74}$ In recent years, the idea that exosomes can affect and modulate the gene expression programs of recipient cells by intercellular signaling has come to be accepted, but to which extent miRNAs account for this mechanism is an issue we are just beginning to understand. Kogure et $\mathrm{al}^{79}$ showed that there is a unique set of eleven miRNAs expressed exclusively in exosomes derived from Hep3B human hepatocellular carcinoma cells and that this set of miRNAs targets genes predominantly involved in transforming growth factor beta activated kinase-1 (TAK1) signaling. Strikingly, these TR exosomes can modulate the constitutive expression of TAK1 and modulate downstream signaling associated with TAK1 in recipient Hep3B cells. ${ }^{79}$ The evidence provided by Shen et $\mathrm{al}^{54}$ in the sense that EGFR regulates the maturation of miRNAs in a trafficking-associated mechanism is thought-provoking concerning the functional relevance miRNAs secreted by TR exosomes hold in cancer. Exosomes in cancer have multiple functions including promotion of certain local and systemic processes that lead to cell growth and dissemination, or impairment of the immune system response. In fact, there is growing evidence that TR exosomes might act as a vehicle for suppressive signals and have suppressive effects on antitumor immune responses. ${ }^{80,81}$ On the other hand, it has been found that macrophages regulate invasiveness of cancer cells through exosome-mediated delivery of oncogenic miRNAs. ${ }^{82}$

\section{Role of miRNAs transported by exosomes in metastasis}

The metastatic process involves the manipulation of the cellular microenvironment to optimize conditions for deposition and growth both locally and at a distance. ${ }^{83,84}$ The discovery that miRNAs can function as hormones, entering the circulatory system and travelling to distant organs to deliver their message, where they are actively taken up by recipient cells located there, has pointed to the potential of these regulatory molecules as signals involved in preparing the distant site for tumor colonization. ${ }^{2,68}$ On the other hand, it is well established that TR exosomes are contributors to both formation of primary tumors and metastases. In this section, we present examples on how miRNAs secreted in TR exosomes participate in preparing and promoting the metastatic process in cancer. In one such example, it was shown that exosomes released by CD105 cancer stem cells from renal carcinomas may modify the tumor microenvironment by triggering angiogenesis and may promote formation of a pre-metastatic niche. ${ }^{13}$ Interestingly, these vesicles were enriched in miRNAs, which may modulate several biological functions relevant in tumor invasion and metastasis. ${ }^{13}$

To support the role of miRNAs secreted in TR exosomes in modulating the tumor microenvironment, Zhang et $\mathrm{al}^{85}$ found that THP-1-derived (the acute monocytic leukemia cell line) exosomes are incorporated into human HMEC-1 (the human mammary epithelial cell line) cells and deliver miR-150. The elevated exogenous miR-150 effectively reduces c-Myb expression enhancing cell migration. ${ }^{85}$ Exosomes released from dendritic cells can fuse with target 
dendritic cells and release their contents into the target cells, leading to mRNA silencing. ${ }^{86}$ A collection of studies from different groups provides evidence that miRNAs delivered by TR exosomes into recipient cells can regulate target gene expression and recipient cell function, modulating the tumor microenvironment to adapt it for tumor promotion and progression. This role of miRNAs acting on neighboring cells to transmit a message produced by a donor cell and taken up by a recipient cell resembles a paracrine mechanism of intercellular communication.

In 2008, Hunter et $\mathrm{al}^{87}$ identified miRNAs in circulating MVs in the plasma and in peripheral blood mononuclear cells. Interestingly, many of the miRNAs characterized in this study were predicted to regulate homeostasis of hematopoietic cells and metabolic functions. More recently, Hood et $\mathrm{al}^{83}$ found that melanoma exosomes are capable of directly tuning a remote lymph node into a microenvironment that facilitates melanoma growth and metastasis even in the local absence of tumor cells. This work provides evidence that TR exosomes can act as a messenger mechanism to signal sites to prepare for eventual metastasis. In recent years, multiple studies have demonstrated the presence of TR exosome miRNAs in circulation. ${ }^{33,35,87}$

Until recently, it was believed that miRNAs transported by exosomes exerted their signaling function by regulating the expression of their target mRNA transcripts in the recipient cell. Interestingly, Fabbri et al ${ }^{88,89}$ recently demonstrated that miR-21 and -29a secreted by tumor cells via exosomes could bind to toll-like receptor 8 (TLR8) (and TLR7) and activate these receptors on immune cells, leading to TLR-mediated NF- $\kappa \mathrm{B}$ (nuclear factor kappalight-chain-enhancer of activated B cells) activation and secretion of prometastatic inflammatory cytokines that may ultimately lead to tumor growth and metastasis. This paramount work does not describe the known molecular function of miRNAs secreted in exosomes, but rather identifies a whole new role, in which miRNAs act as key regulators of the tumor microenvironment by acting as paracrine agonists of TLRs. ${ }^{88,89}$ Although these studies support the idea that miRNAs can regulate the different pathways by which cells invade and metastasize to a diversity of sites and organs within the body, the picture is far from complete. In fact, the process of miRNA selection to be packaged and secreted in exosomes derived from tumor cells is affected by the malignant transformation itself. Moreover, accumulating data indicate that vesicles from multiple cells interact with or enter different target cells from other tissues, altering their phenotype, ${ }^{90}$ which poses new questions about the specificity and tropism of exosomes in a particular environment.

\section{Potential of exosome-derived miRNAs as biomarkers: the informant passenger}

To date, different authors have discussed the latest developments in the use of circulating miRNAs as prognostic and predictive biomarkers and their utility in personalized medicine. (For a very recent and comprehensive review on this topic, see Schwarzenbach et al. ${ }^{105}$ Here, we highlight the efforts aimed at the characterization of miRNAs derived from TR exosomes as surrogate biomarkers of cancer. Different groups have detected miRNAs from TR exosomes in patient plasma of different tumors such as lung cancer, ${ }^{75,91-95}$ glioblastoma multiforme (GBM), ${ }^{33,96}$ malignant glioma, ${ }^{33}$ gastric cancer, ${ }^{11}$ breast cancer, ${ }^{56,97,98}$ prostate cancer, ${ }^{99-101}$ ovarian carcinoma, ${ }^{32}$ and cervical cancer ${ }^{102}$ (Table 1 ). It is widely accepted that resistance to therapy and relapse of cancer remains a central problem in cancer treatment, and this process accounts for much cancer mortality. There is increasing evidence that miRNAs are potential biomarkers for diagnosis and prognosis, and also to monitor treatment response. ${ }^{103}$ Due to the fact that exosomes are released in accessible body fluids such as blood and urine, and can be isolated by minimally invasive methods, miRNAs in exosomes represent a promising biomedical tool, useful as biomarkers in the diagnosis and prognosis of malignant tumors. ${ }^{104,105}$ In 2008, Mitchell et $\mathrm{a}^{66}$ showed that serum levels of miR-141, a miRNA expressed in prostate cancer, can distinguish patients with prostate cancer from healthy subjects. By this means, they established proof of the principle that tumor-derived miRNAs enter the circulation where their measurement in plasma can serve as a means for cancer detection. ${ }^{66} \mathrm{~A}$ few years later, Bryant et $\mathrm{al}^{101}$ demonstrated significant upregulation of miRNAs derived from TR exosomes in metastatic prostate cancer patients compared with non-recurrent cancer patients. Taylor and Gercel-Taylor ${ }^{32}$ demonstrated the association of miRNAs with circulating tumor-derived exosomes and found that although Epithelial cell adhesion molecule (EpCAM)-positive exosomes were detectable in patients with both benign ovarian disease and ovarian cancer, exosomal miRNA from ovarian cancer patients had similar profiles, which were significantly different from profiles observed in benign disease. In breast cancer, it has been shown that the release of miRNAs from cells into blood, milk, and ductal fluids is selective, and that the selection of released miRNAs may correlate with malignancy. ${ }^{56}$ A different study showed that serum exosomes isolated from patients with esophageal squamous cell carcinoma (ESCC) induces the proliferation of 
Table I MiRNAs from tumor-derived exosomes isolated from different body fluids or cell types with potential use as biomarkers

\begin{tabular}{|c|c|c|c|}
\hline Tumor type & Relevant miRNA content & Sample or cell of origin & Study \\
\hline Lung adenocarcinoma & $\begin{array}{l}\text { miR-I7-3p, miR-2I, miR-106a, miR-I46, miR-I55, } \\
\text { miR-19I, miR-192, miR-203, miR-205, miR-2I0, } \\
\text { miR-2I2, miR-2I4 }\end{array}$ & Peripheral blood & $\begin{array}{l}\text { Rabinowits } \\
\text { et } \mathrm{al}^{75}\end{array}$ \\
\hline Non-small-cell lung cancer & let-7f and miR-30e-3p & Plasma & Silva et $\mathrm{al}^{91}$ \\
\hline Lung adenocarcinoma & miR-2I, miR-I33b, miR-98, and miR-I8Ia & Lung cancer cell line: A549 & Xiao et $\mathrm{al}^{93}$ \\
\hline Lung squamous cell carcinoma & miR-205, miR-19a, miR-19b, miR-30b, and miR-20a & Plasma & Aushev et $\mathrm{al}^{94}$ \\
\hline Lung adenocarcinoma & $\begin{array}{l}\text { miR-378a, miR-379, miR-139-5p, and miR-200b-5p; } \\
\text { miR-I5Ia-5p, miR-30a-3p, miR-200b-5p, } \\
\text { miR-629, miR-100, and miR-I54-3p }\end{array}$ & Plasma & Cazzoli et al ${ }^{95}$ \\
\hline GBM & miR-2I & Serum & Skog et al, ${ }^{33}$ \\
\hline GBM & $\begin{array}{l}\text { miR-I469, miR-320b, miR-320c, miR-I9I, } \\
\text { miR-222, Let-7a, miR-923, miR-I308, miR-3I85, } \\
\text { miR-35I-5p, miR-25, miR-939, miR-30c, miR-422a, } \\
\text { miR-22I, miR-487a, miR-335*, and miR-4329 }\end{array}$ & $\begin{array}{l}\text { GBM cell lines: } \\
\text { LNI8 and U87MG }\end{array}$ & Arscott et al, ${ }^{96}$ \\
\hline Gastric cancer & miR-2I4, miR-22I and miR-222 & $\begin{array}{l}\text { Cancer tissue-derived } \\
\text { mesenchymal stem cells }\end{array}$ & Wang et al" \\
\hline Breast cancer & miR-I6, miR-I246, miR-45I and miR-720 & $\begin{array}{l}\text { Breast cancer cell line MCF7 cells, } \\
\text { breast ductal lavages, milk and blood }\end{array}$ & Pigati et $\mathrm{al}^{56}$ \\
\hline Breast cancer & miR-200a, miR-200c and miR-205 & Serum & Rupp et $\mathrm{al}^{97}$ \\
\hline $\begin{array}{l}\text { Basal-like ductal } \\
\text { breast carcinoma }\end{array}$ & miR-I40, miR-29a, and miR-2I & $\begin{array}{l}\text { Tumor isolated CD49f+l } \\
\text { CD24- stem-like cells }\end{array}$ & Li et $\mathrm{al}^{98}$ \\
\hline Prostate cancer & miR-|4| & Serum & Mitchell et $\mathrm{al}^{66}$ \\
\hline Prostate cancer & $\begin{array}{l}\text { miR-4258, miR-7II, miR-22I, miR-193a-3p, } \\
\text { miR-30e, miR-I297, miR-I29* and miR-2I* }\end{array}$ & Prostate cancer cell line: PC3 & Hessvik et al ${ }^{99}$ \\
\hline Prostate cancer & $\operatorname{miR}-485-3 p$ & Prostate cancer cell line: DU-I45 & Lucotti et al ${ }^{100}$ \\
\hline Prostate cancer & miR-I07, miR-I4I, miR-375, and miR-574-3p & Blood, urine sediment and tissue & Bryant et al ${ }^{101}$ \\
\hline Ovarian cancer & $\begin{array}{l}\text { miR-2I, miR-I4I, miR-200a, miR-200c, } \\
\text { miR-200b, miR-203, miR-205, and miR-2 I4 }\end{array}$ & Serum & Taylor et $\mathrm{al}^{32}$ \\
\hline Cervical cancer & miR-2I and miR-I46a & Cervicovaginal lavage & Liu et $\mathrm{al}^{102}$ \\
\hline $\begin{array}{l}\text { Esophageal squamous } \\
\text { cell carcinoma }\end{array}$ & $\operatorname{miR}-2 I$ & Serum & Tanaka et al ${ }^{106}$ \\
\hline Hepatocellular carcinoma & $\begin{array}{l}\text { miR-584, miR-5I7c, miR-378, miR-520f, } \\
\text { miR-I42-5p, miR-45I, miR-5I8d, miR-2I5, } \\
\text { miR-376a*, miR-I33b, and miR-367 }\end{array}$ & Hepatocyte carcinoma cell line & Kogure et $\mathrm{al}^{79}$ \\
\hline
\end{tabular}

Abbreviations: GBM, glioblastoma multiforme; miRNA, microRNA.

ESCC cells in vitro. Moreover, the authors found that exosomal miR-21 expression is upregulated in serum from patients with ESCC, and this alteration was positively correlated with tumor progression and aggressiveness. ${ }^{106} \mathrm{In}$ a recent work, it was found that exposure of A549 lung cancer cells to cisplatin could cause cells to release more exosomes than in normal conditions, and that the interaction of these exosomes with other A549 cells could increase the resistance of these cells to cisplatin. ${ }^{93}$ Another study recently conducted demonstrated that miRNAs derived from TR exosomes after irradiation could be used as indicators of resistance to radiotherapy in GBM. ${ }^{96}$ In lung cancer, Aushev et $\mathrm{a}^{94}$ compared circulating miRNA profiles in patients with lung squamous cell carcinoma before and after tumor removal, assuming that the levels of all tumor-relevant miRNAs would drop after the surgery. These authors discovered a specific panel of the miRNAs whose levels decreased strikingly in the blood of patients after lung squamous cell carcinoma surgery.
Interestingly some of these miRNAs were selectively secreted in exosomes. In light of these and other findings, it is plausible that the miRNAs enriched in different body fluids are derived from exosomes released by tumor cells under a specific set of stimuli. Therefore, the miRNA content in body fluids may represent the result of a highly refined process of cargo selection, uploading, and secretion in exosomes, and provides reliable information about the identity and status of the cell type from which they are derived and perhaps about the recipient cell, in the setting of the cellular heterogeneity that is characteristic of malignancies.

\section{Therapeutic potential of exosome- derived miRNAs in cancer}

Because of their small size and ability to cross biological membranes and protect their mRNA, miRNA, and protein cargo from degradation, exosomes are ideal delivery systems 


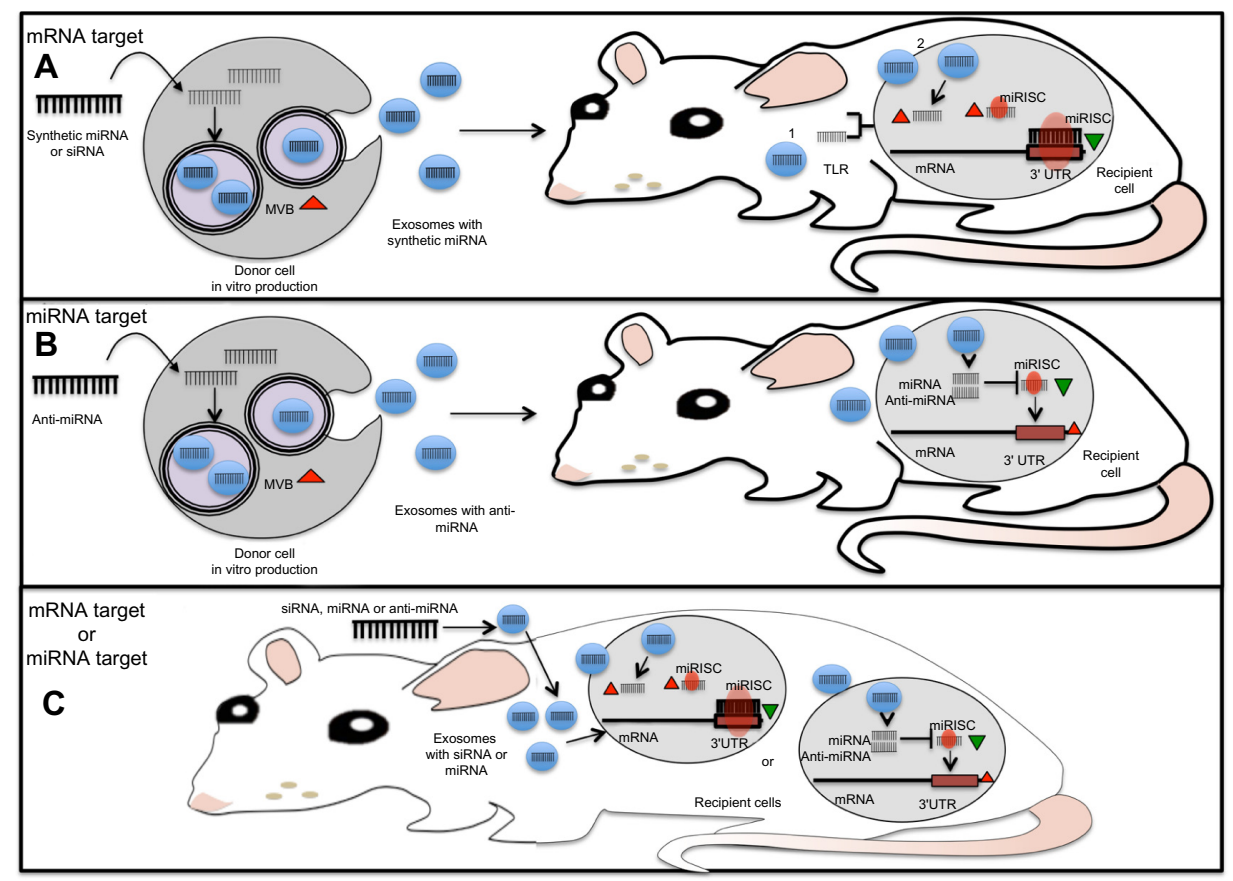

Figure 3 Molecular approaches for the use of miRNAs derived from TR exosomes as therapeutic tools.

Notes: Exosomes are ideal delivery systems that can be manipulated for the administration of specific molecules such as synthetic miRNAs or anti-miRNAs. (A) Synthetic miRNAs may be transfected into an exosome-producing cell (eg, mesenchymal stem cell). Transfected miRNAs are released and delivered to the recipient cell via exosomes. Once they reach the recipient cell, synthetic miRNAs bind and arrest the translation of their canonical target transcripts (I). MiRNAs can also act like ligands to activate membrane surface receptors (2). (B) In a similar strategy, anti-miRNA molecules are transfected into exosome-producing cells, where they reduce the levels of endogenous miRNAs in the donor cell, thus diminishing the amount of miRNAs transferred to the recipient cells. (C) Alternatively, anti-miRNA molecules can be directly transduced into exosomes and delivered to the recipient cell, where they prevent miRNAs from silencing their cognate mRNA. In a similar fashion, siRNA molecules can be employed to downregulate mRNA targets.

Abbreviations: miRNA, microRNA; mRNA, messenger RNA; MVB, multivesicular body; RISC, RNA-induced silencing complex; siRNA, short interfering RNA; TLR, tolllike receptor; TR, tumor-released; UTR, untranslated region.

that can be manipulated for the transfer of specific molecules such as miRNAs or anti-miRNAs (Figure 3). In an attempt to block miR-9, which is overexpressed in GBM cells and impairs the response to temozolomide, Munoz et a ${ }^{107}$ refined a method for the delivery of an anti-miR-9 molecule from mesenchymal stem cells (MSCs) via release of exosometype microvesicles. They demonstrated that anti-miR-9 was transferred from MSCs to GBM cells. The delivery of anti-miR-9 to the resistant GBM cells reversed the expression of the multidrug transporter and sensitized the GBM cells to temozolomide, as shown by increased cell death and caspase activity, thus illustrating a potential role for MSCs in the functional delivery of synthetic anti-miR-9 to reverse chemoresistance of GBM cells. ${ }^{107}$ To reinforce the evidence that TR exosomes can serve as vehicles for the delivery of synthetic miRNAs or miRNA inhibitors, a proof of concept study tested whether MSC exosomes could be used as a vehicle for delivery of anti-tumor miRNAs. A miR-146b expression plasmid was transfected into MSCs, and exosomes released by the transfected MSCs were harvested. The study found that intra-tumoral injection of exosomes derived from
miR-146-expressing MSCs significantly reduced glioma xenograft growth in a rat model of a primary brain tumor. ${ }^{108}$ Various approaches have made use of TR exosomes as immune modulators. ${ }^{109,110}$ However, to our knowledge none of these works have specifically demonstrated the participation of the miRNAs contained in the TR exosomes as modulator molecules in the communication process that influences the immune cell response. Nevertheless, it is highly plausible that miRNA cargo from TR exosomes somehow regulates and helps to reprogram the immune response in cancer. ${ }^{111}$

To realize the potential of exosomes as miRNA-based drugs, it is necessary to develop more efficient and tissuespecific ways for their delivery. In a paramount work, Alvarez-Erviti et al ${ }^{112}$ developed a method to produce exosomes from self-derived dendritic cells. Dendritic cells were engineered to elicit neuron-specific targeting. Interestingly, after purification of the exosomes released, they loaded them with an exogenous siRNA against $B A C E 1$, a therapeutic target in Alzheimer's disease, in wild-type mice. The delivery of this exosome-mediated siRNA produced a significant reduction in protein levels in a tissue-specific manner, and these 
authors point out that nonspecific uptake in other tissues was not observed. ${ }^{112}$ More recently, the therapeutic potential of exosome-mediated siRNA delivery was demonstrated in vitro by the strong knockdown of $R A D 51$, a prospective therapeutic target for cancer cells. ${ }^{113}$ Targeting the machinery of production and release of TR exosomes constitutes another potential therapeutic application in cancer. ${ }^{114-116}$ Rab27, a member of the Guanosine-5'-triphosphate-activating proteins that regulate exosome secretion, ${ }^{117,118}$ is upregulated in breast cancer, and its elevation is correlated with the presence of lymph node metastasis and advanced clinical stage; furthermore, a significant positive relationship has been observed between Rab27b and epithelial mesenchymal transition markers. ${ }^{119}$ Moreover, Rab35 inactivation results in the intracellular accumulation of the vesicles and alters exosome secretion. ${ }^{118}$ In a different example, upregulation of heparanase, an enzyme that cleaves heparan sulfate, enhances exosome secretion in diverse human cancer cell lines. ${ }^{120}$ Mechanical changes can also affect exosome release. For instance, recent data show that loss of adherence in breast cancer cells may induce rapid exosome secretion. ${ }^{121}$ Finally, there are some data about specific exosome uptake mechanisms. One signaling pathway reported in ovarian carcinoma suggests that tumoral exosomes require the expression of phosphatidyl-serine at the exosomal surface to be taken up by natural killer cells. ${ }^{122}$ These reports suggest that by targeting the molecular machinery of exosome production, it is possible to inhibit the pro-oncogenic information carried by TR exosomes, including those messages in the form of miRNAs. A better understanding on the mechanism that regulates the production, secretion, and uptake of exosomes will allow us to tailor exosomes to be selectively delivered to a specific target cell. Indeed, Ohno et $\mathrm{al}^{123}$ recently reported that by engineering donor cells to produce modified exosomes with GE11, a peptide that binds to EGFR, expressed in their surfaces could efficiently deliver let-7a miRNA to EGFRexpressing breast cancer cells. Interestingly, the authors showed that GE11-positive exosomes containing let-7 inhibit tumor development in vivo.

\section{Disadvantages of using exosomes in cancer therapy}

We have pointed out that exosomal miRNAs are capable of affecting a variety of physiological and pathological conditions. Moreover, exploiting the exosome feature as natural carriers of miRNAs ${ }^{113}$ may provide new strategies to develop novel siRNA and miRNA delivery systems as anti-cancer therapy. ${ }^{124}$ Although, TR exosomes have been proven to be tissue and cell specific, therapeutic potential of exosomes in cancer is largely unknown, and further research is necessary, ${ }^{107,112,123}$ before they can be used clinically. Firstly, TR exosomes incorporate a variety of cellular factors mediating oncogenic and proliferative properties; ${ }^{33,93,125,126}$ more research is required to gain knowledge on the complexity of exosome cargo and the possible interference of unknown secreted factors. Secondly, the biocompatibility between donor and recipient tissues needs to be evaluated; some studies conducted so far highlight the value of using self-derived exosomes to reduce toxicity and ensure immune compatibility. ${ }^{12,127}$ As has been discussed, there is evidence that argues in favor of a variety of uptake mechanisms by recipient cells. ${ }^{114-116}$ This evidence leads us to ask about the possibility that exosomes from different origins have an effect onto the same cell type. Furthermore, some physical and molecular stimuli could sensitize cells for the release and uptake of exosomes. In this regard, it has been reported that exososome secretion from normal human mammary epithelial cells and breast cancer cells is stimulated when exposed to a medium containing its own exosomes. ${ }^{128}$ While this study unravel a novel feedback regulatory mechanism for controlling exosome release, the biological and functional consequences of this phenomenon in cancer remains to be answered.

\section{Concluding remarks}

This review focuses on the recent literature on miRNA secretion through exosomes and its implications in the process of tumorigenesis. It has been established that exosomes are efficient transporters of multiple signals in intercellular communication, as they allow for delivery of messages regardless of the distance between donor and recipient cells. Several studies have found that exosomes are present in a variety of body fluids and blood. There is growing evidence that these vesicles are particularly enriched in miRNAs. Based on the multiple functions that these miRNA molecules can exert, it seems likely that they may be involved in altering the behavior of recipient cells. Although several studies have shown that cancer cells make use of this mechanism to alter their surrounding microenvironment to promote tumor growth and invasiveness and prepare potential distant sites for metastasis, further research is needed. Firstly, we need to improve our understanding of the mechanisms of sorting, secretion, and uptake of miRNAs contained in exosomes. Secondly, it is important to acquire an understanding of the function of exosome miRNAs in physiological conditions, including but not limited to embryogenesis, organogenesis, 
and maintaining tissue and organ homeostasis. Finally, the potential of exosomes to deliver miRNAs, and the fact that the latter can act as multifunctional molecules, makes them an attractive approach in the development of therapeutic strategies against tumor cells.

\section{Disclosure}

The authors report no conflicts of interest in this work.

\section{References}

1. Domhan S, Ma L, Tai A, et al. Intercellular communication by exchange of cytoplasmic material via tunneling nano-tube like structures in primary human renal epithelial cells. PLoS One. 2011;6(6):e21283.

2. Mittelbrunn M, Sanchez-Madrid F. Intercellular communication: diverse structures for exchange of genetic information. Nat Rev Mol Cell Biol. 2012;13(5):328-335.

3. Valadi H, Ekstrom K, Bossios A, Sjostrand M, Lee JJ, Lotvall JO. Exosome-mediated transfer of mRNAs and microRNAs is a novel mechanism of genetic exchange between cells. Nat Cell Biol. 2007;9(6): 654-659.

4. Cortez MA, Bueso-Ramos C, Ferdin J, Lopez-Berestein G, Sood AK, Calin GA. MicroRNAs in body fluids - the mix of hormones and biomarkers. Nat Rev Clin Oncol. 2011;8(8):467-477.

5. Hoy AM, Buck AH. Extracellular small RNAs: what, where, why? Biochem Soc Trans. 2012;40(4):886-890.

6. Lotvall J, Valadi H. Cell to cell signalling via exosomes through esRNA. Cell Adh Migr. 2007;1(3):156-158.

7. Hu G, Drescher KM, Chen XM. Exosomal miRNAs: biological properties and therapeutic potential. Front Genet. 2012;3:56.

8. Palma J, Yaddanapudi SC, Pigati L, et al. MicroRNAs are exported from malignant cells in customized particles. Nucleic Acids Res. 2012;40(18):9125-9138.

9. Lee Y, El Andaloussi S, Wood MJ. Exosomes and microvesicles: extracellular vesicles for genetic information transfer and gene therapy. Hum Mol Genet. 2012;21(R1):R125-R134.

10. Kim J, Morley S, Le M, et al. Enhanced shedding of extracellular vesicles from amoeboid prostate cancer cells: potential effects on the tumor microenvironment. Cancer Biol Ther. 2014;15(4):409-418.

11. Wang M, Zhao C, Shi H, et al. Deregulated microRNAs in gastric cancer tissue-derived mesenchymal stem cells: novel biomarkers and a mechanism for gastric cancer. Br J Cancer. 2014;110(5): 1199-1210.

12. Webber JP, Spary LK, Sanders AJ, et al. Differentiation of tumourpromoting stromal myofibroblasts by cancer exosomes. Oncogene. Epub January 20, 2014.

13. Grange C, Tapparo M, Collino F, et al. Microvesicles released from human renal cancer stem cells stimulate angiogenesis and formation of lung premetastatic niche. Cancer Res. 2011;71(15):5346-5356.

14. Beckham CJ, Olsen J, Yin PN, et al. Bladder cancer exosomes contain EDIL-3/Del1 and facilitate cancer progression. $J$ Urol. Epub February 13, 2014.

15. Yang L, Wu X, Wang D, Luo C, Chen L. Renal carcinoma cell-derived exosomes induce human immortalized line of Jurkat T lymphocyte apoptosis in vitro. Urol Int. 2013;91(3):363-369.

16. Reiners KS, Topolar D, Henke A, et al. Soluble ligands for NK cell receptors promote evasion of chronic lymphocytic leukemia cells from NK cell anti-tumor activity. Blood. 2013;121(18):3658-3665.

17. Luga V, Wrana JL. Tumor-stroma interaction: Revealing fibroblastsecreted exosomes as potent regulators of Wnt-planar cell polarity signaling in cancer metastasis. Cancer Res. 2013;73(23):6843-6847.

18. Mu W, Rana S, Zoller M. Host matrix modulation by tumor exosomes promotes motility and invasiveness. Neoplasia. 2013;15(8):875-887.

19. Chen X, Liang H, Zhang J, Zen K, Zhang CY. Secreted microRNAs: a new form of intercellular communication. Trends Cell Biol. 2012;22(3): $125-132$.
20. Azmi AS, Bao B, Sarkar FH. Exosomes in cancer development, metastasis, and drug resistance: a comprehensive review. Cancer Metastasis Rev. 2013;32(3-4):623-642.

21. Trams EG, Lauter CJ, Salem N Jr, Heine U. Exfoliation of membrane ecto-enzymes in the form of micro-vesicles. Biochim Biophys Acta. 1981;645(1):63-70.

22. Harding C, Heuser J, Stahl P. Receptor-mediated endocytosis of transferrin and recycling of the transferrin receptor in rat reticulocytes. $J$ Cell Biol. 1983;97(2):329-339.

23. Johnstone RM. Exosomes biological significance: a concise review. Blood Cells Mol Dis. 2006;36(2):315-321.

24. Pant S, Hilton H, Burczynski ME. The multifaceted exosome: biogenesis, role in normal and aberrant cellular function, and frontiers for pharmacological and biomarker opportunities. Biochem Pharmacol. 2012;83(11):1484-1494.

25. Mathivanan S, Fahner CJ, Reid GE, Simpson RJ. ExoCarta 2012: database of exosomal proteins, RNA and lipids. Nucleic Acids Res. 2012;40(Database issue):D1241-D1244.

26. Crescitelli R, Lasser C, Szabo TG, et al. Distinct RNA profiles in subpopulations of extracellular vesicles: apoptotic bodies, microvesicles and exosomes. $J$ Extracell Vesicles. 2013;2.

27. Fang Y, Wu N, Gan X, Yan W, Morrell JC, Gould SJ. Higher-order oligomerization targets plasma membrane proteins and HIV gag to exosomes. PLoS Biol. 2007;5(6):e158.

28. Conde-Vancells J, Rodriguez-Suarez E, Embade N, et al. Characterization and comprehensive proteome profiling of exosomes secreted by hepatocytes. J Proteome Res. 2008;7(12):5157-5166.

29. Simpson RJ, Lim JW, Moritz RL, Mathivanan S. Exosomes: proteomic insights and diagnostic potential. Expert Rev Proteomics. 2009;6(3): 267-283.

30. Thery C, Boussac M, Veron P, et al. Proteomic analysis of dendritic cell-derived exosomes: a secreted subcellular compartment distinct from apoptotic vesicles. J Immunol. 2001;166(12):7309-7318.

31. Mayers JR, Audhya A. Vesicle formation within endosomes: an ESCRT marks the spot. Commun Integr Biol. 2012;5(1):50-56.

32. Taylor DD, Gercel-Taylor C. MicroRNA signatures of tumor-derived exosomes as diagnostic biomarkers of ovarian cancer. Gynecol Oncol. 2008;110(1):13-21.

33. Skog J, Wurdinger T, van Rijn S, et al. Glioblastoma microvesicles transport RNA and proteins that promote tumour growth and provide diagnostic biomarkers. Nat Cell Biol. 2008;10(12):1470-1476.

34. Lawrie CH, Gal S, Dunlop HM, et al. Detection of elevated levels of tumour-associated microRNAs in serum of patients with diffuse large B-cell lymphoma. Br J Haematol. 2008;141(5):672-675.

35. Zomer A, Vendrig T, Hopmans ES, van Eijndhoven M, Middeldorp JM, Pegtel DM. Exosomes: fit to deliver small RNA. Commun Integr Biol. 2010;3(5):447-450.

36. Doench JG, Petersen CP, Sharp PA. siRNAs can function as miRNAs. Genes Dev. 2003;17(4):438-442.

37. Elbashir SM, Harborth J, Lendeckel W, Yalcin A, Weber K, Tuschl T. Duplexes of 21-nucleotide RNAs mediate RNA interference in cultured mammalian cells. Nature. 2001;411(6836):494-498.

38. Peralta-Zaragoza O, Bermudez-Morales VH, Madrid-Marina V. [RNA interference: biogenesis molecular mechanisms and its applications in cervical cancer]. Rev Invest Clin. 2010;62(1):63-80. Spanish.

39. Raiborg C, Stenmark H. The ESCRT machinery in endosomal sorting of ubiquitylated membrane proteins. Nature. 2009;458(7237):445-452.

40. Tamai K, Tanaka N, Nakano T, et al. Exosome secretion of dendritic cells is regulated by Hrs, an ESCRT-0 protein. Biochem Biophys Res Commun. 2010;399(3):384-390.

41. Wollert T, Hurley JH. Molecular mechanism of multivesicular body biogenesis by ESCRT complexes. Nature. 2010;464(7290):864-869.

42. Fevrier B, Raposo G. Exosomes: endosomal-derived vesicles shipping extracellular messages. Curr Opin Cell Biol. 2004;16(4): 415-421.

43. Kim VN, Han J, Siomi MC. Biogenesis of small RNAs in animals. Nat Rev Mol Cell Biol. 2009;10(2):126-139. 
44. Han J, Lee Y, Yeom KH, Kim YK, Jin H, Kim VN. The Drosha-DGCR8 complex in primary microRNA processing. Genes Dev. 2004;18(24): 3016-3027.

45. Lee Y, Ahn C, Han J, et al. The nuclear RNase III Drosha initiates microRNA processing. Nature. 2003;425(6956):415-419.

46. Esquela-Kerscher A, Slack FJ. Oncomirs - microRNAs with a role in cancer. Nat Rev Cancer. 2006;6(4):259-269.

47. Suzuki HI, Miyazono K. Emerging complexity of microRNA generation cascades. J Biochem. 2011;149(1):15-25.

48. Bartel DP. MicroRNAs: genomics, biogenesis, mechanism, and function. Cell. 2004;116(2):281-297.

49. Cai X, Hagedorn CH, Cullen BR. Human microRNAs are processed from capped, polyadenylated transcripts that can also function as mRNAs. RNA. 2004;10(12):1957-1966

50. Thomas M, Lieberman J, Lal A. Desperately seeking microRNA targets. Nat Struct Mol Biol. 2010;17(10):1169-1174.

51. Gibbings DJ, Ciaudo C, Erhardt M, Voinnet O. Multivesicular bodies associate with components of miRNA effector complexes and modulate miRNA activity. Nat Cell Biol. 2009;11(9):1143-1149.

52. Lee YS, Pressman S, Andress AP, et al. Silencing by small RNAs is linked to endosomal trafficking. Nat Cell Biol. 2009;11(9):1150-1156.

53. Villarroya-Beltri C, Gutierrez-Vazquez C, Sanchez-Cabo F, et al. Sumoylated hnRNPA2B1 controls the sorting of miRNAs into exosomes through binding to specific motifs. Nat Commun. 2013;4:2980.

54. Shen J, Xia W, Khotskaya YB, et al. EGFR modulates microRNA maturation in response to hypoxia through phosphorylation of AGO2. Nature. 2013;497(7449):383-387.

55. Chen TS, Lai RC, Lee MM, Choo AB, Lee CN, Lim SK. Mesenchymal stem cell secretes microparticles enriched in pre-microRNAs. Nucleic Acids Res. 2010;38(1):215-224.

56. Pigati L, Yaddanapudi SC, Iyengar R, et al. Selective release of microRNA species from normal and malignant mammary epithelial cells. PLoS One. 2010;5(10):e13515.

57. Li L, Zhu D, Huang L, et al. Argonaute 2 complexes selectively protect the circulating microRNAs in cell-secreted microvesicles. PLoS One. 2012;7(10):e46957.

58. Zhou Q, Li M, Wang X, et al. Immune-related microRNAs are abundant in breast milk exosomes. Int J Biol Sci. 2012;8(1):118-123.

59. Balaj L, Lessard R, Dai L, et al. Tumour microvesicles contain retrotransposon elements and amplified oncogene sequences. Nat Commun. 2011;2:180.

60. Bergsmedh A, Szeles A, Henriksson M, et al. Horizontal transfer of oncogenes by uptake of apoptotic bodies. Proc Natl Acad Sci U S A. 2001;98(11):6407-6411.

61. Ehnfors J, Kost-Alimova M, Persson NL, et al. Horizontal transfer of tumor DNA to endothelial cells in vivo. Cell Death Differ. 2009;16(5): 749-757.

62. Deregibus MC, Cantaluppi V, Calogero R, et al. Endothelial progenitor cell derived microvesicles activate an angiogenic program in endothelial cells by a horizontal transfer of mRNA. Blood. 2007;110(7): 2440-2448.

63. Benner SA. Extracellular 'communicator RNA'. FEBS Lett. 1988;233(2):225-228.

64. Chen X, Ba Y, Ma L, et al. Characterization of microRNAs in serum: a novel class of biomarkers for diagnosis of cancer and other diseases. Cell Res. 2008;18(10):997-1006.

65. Chim SS, Shing TK, Hung EC, et al. Detection and characterization of placental microRNAs in maternal plasma. Clin Chem. 2008;54(3): 482-490.

66. Mitchell PS, Parkin RK, Kroh EM, et al. Circulating microRNAs as stable blood-based markers for cancer detection. Proc Natl Acad Sci U $S$ A. 2008;105(30):10513-10518.

67. Weber JA, Baxter DH, Zhang S, et al. The microRNA spectrum in 12 body fluids. Clin Chem. 2010;56(11):1733-1741.

68. Shah MY, Calin GA. The mix of two worlds: non-coding RNAs and hormones. Nucleic Acid Ther. 2013;23(1):2-8.

69. Ji X, Takahashi R, Hiura Y, Hirokawa G, Fukushima Y, Iwai N. Plasma miR-208 as a biomarker of myocardial injury. Clin Chem. 2009;55(11): 1944-1949.
70. Arroyo JD, Chevillet JR, Kroh EM, et al. Argonaute2 complexes carry a population of circulating microRNAs independent of vesicles in human plasma. Proc Natl Acad Sci U S A. 2011;108(12): 5003-5008.

71. Vickers KC, Palmisano BT, Shoucri BM, Shamburek RD, Remaley AT. MicroRNAs are transported in plasma and delivered to recipient cells by high-density lipoproteins. Nat Cell Biol. 2011;13(4): 423-433.

72. Keller S, Ridinger J, Rupp AK, Janssen JW, Altevogt P. Body fluid derived exosomes as a novel template for clinical diagnostics. J Transl Med. 2011;9:86.

73. Reid G, Kirschner MB, van Zandwijk N. Circulating microRNAs: Association with disease and potential use as biomarkers. Crit Rev Oncol Hematol. 2011;80(2):193-208.

74. Ohshima K, Inoue K, Fujiwara A, et al. Let-7 microRNA family is selectively secreted into the extracellular environment via exosomes in a metastatic gastric cancer cell line. PLoS One. 2010; 5(10): e13247.

75. Rabinowits G, Gercel-Taylor C, Day JM, Taylor DD, Kloecker GH. Exosomal microRNA: a diagnostic marker for lung cancer. Clin Lung Cancer. 2009;10(1):42-46.

76. Smalheiser NR. Exosomal transfer of proteins and RNAs at synapses in the nervous system. Biol Direct. 2007;2:35

77. Baj-Krzyworzeka M, Szatanek R, Weglarczyk K, et al. Tumour-derived microvesicles carry several surface determinants and mRNA of tumour cells and transfer some of these determinants to monocytes. Cancer Immunol Immunother. 2006;55(7):808-818.

78. Pegtel DM, Cosmopoulos K, Thorley-Lawson DA, et al. Functional delivery of viral miRNAs via exosomes. Proc Natl Acad Sci U S A. 2010;107(14):6328-6333.

79. Kogure T, Lin WL, Yan IK, Braconi C, Patel T. Intercellular nanovesicle-mediated microRNA transfer: a mechanism of environmental modulation of hepatocellular cancer cell growth. Hepatology. 2011;54(4):1237-1248.

80. Filipazzi P, Burdek M, Villa A, Rivoltini L, Huber V. Recent advances on the role of tumor exosomes in immunosuppression and disease progression. Semin Cancer Biol. 2012;22(4):342-349.

81. Taylor DD, Gercel-Taylor C. Exosomes/microvesicles: mediators of cancer-associated immunosuppressive microenvironments. Semin Immunopathol. 2011;33(5):441-454.

82. Yang M, Chen J, Su F, et al. Microvesicles secreted by macrophages shuttle invasion-potentiating microRNAs into breast cancer cells. $\mathrm{Mol}$ Cancer. 2011;10:117.

83. Hood JL, San RS, Wickline SA. Exosomes released by melanoma cells prepare sentinel lymph nodes for tumor metastasis. Cancer Res. 2011;71(11):3792-3801

84. Psaila B, Lyden D. The metastatic niche: adapting the foreign soil. Nat Rev Cancer. 2009;9(4):285-293.

85. Zhang Y, Liu D, Chen X, et al. Secreted monocytic miR-150 enhances targeted endothelial cell migration. Mol Cell. 2010;39(1):133-144.

86. Montecalvo A, Larregina AT, Shufesky WJ, et al. Mechanism of transfer of functional microRNAs between mouse dendritic cells via exosomes. Blood. 2012;119(3):756-766.

87. Hunter MP, Ismail N, Zhang X, et al. Detection of microRNA expression in human peripheral blood microvesicles. PLoS One. 2008;3(11):e3694.

88. Fabbri M, Paone A, Calore F, et al. MicroRNAs bind to Toll-like receptors to induce prometastatic inflammatory response. Proc Natl Acad Sci US A. 2012;109(31):E2110-E2116.

89. Fabbri M, Paone A, Calore F, Galli R, Croce CM. A new role for microRNAs, as ligands of Toll-like receptors. RNA Biol. 2013;10(2): $169-174$.

90. Quesenberry PJ, Aliotta JM. Cellular phenotype switching and microvesicles. Adv Drug Deliv Rev. 2010;62(12):1141-1148.

92. Fortunato O, Boeri M, Verri C, et al. Assessment of circulating microRNAs in plasma of lung cancer patients. Molecules. 2014;19(3): 3038-3054. 
93. Xiao X, Yu S, Li S, et al. Exosomes: decreased sensitivity of lung cancer a549 cells to Cisplatin. PLoS One. 2014;9(2):e89534.

94. Aushev VN, Zborovskaya IB, Laktionov KK, et al. Comparisons of microRNA patterns in plasma before and after tumor removal reveal new biomarkers of lung squamous cell carcinoma. PLoS One. 2013;8(10):e78649.

95. Cazzoli R, Buttitta F, Di Nicola M, et al. microRNAs derived from circulating exosomes as noninvasive biomarkers for screening and diagnosing lung cancer. J Thorac Oncol. 2013;8(9):1156-1162.

96. Arscott WT, Tandle AT, Zhao S, et al. Ionizing radiation and glioblastoma exosomes: implications in tumor biology and cell migration. Transl Oncol. 2013;6(6):638-648.

97. Rupp AK, Rupp C, Keller S, et al. Loss of EpCAM expression in breast cancer derived serum exosomes: role of proteolytic cleavage. Gynecol Oncol. 2011;122(2):437-446.

98. Li Q, Eades G, Yao Y, Zhang Y, Zhou Q. Characterization of a stemlike subpopulation in basal-like ductal carcinoma in situ (DCIS) lesions. J Biol Chem. 2014;289(3):1303-1312.

99. Hessvik NP, Phuyal S, Brech A, Sandvig K, Llorente A. Profiling of microRNAs in exosomes released from PC-3 prostate cancer cells. Biochim Biophys Acta. 2012;1819(11-12):1154-1163.

100. Lucotti S, Rainaldi G, Evangelista M, Rizzo M. Fludarabine treatment favors the retention of miR-485-3p by prostate cancer cells: implications for survival. Mol Cancer. 2013;12(1):52.

101. Bryant RJ, Pawlowski T, Catto JW, et al. Changes in circulating microRNA levels associated with prostate cancer. $\mathrm{Br} J$ Cancer. 2012;106(4):768-774.

102. Liu J, Sun H, Wang X, et al. Increased exosomal microRNA-21 and microRNA-146a levels in the cervicovaginal lavage specimens of patients with cervical cancer. Int J Mol Sci. 2014;15(1):758-773.

103. Sethi S, Ali S, Sarkar FH. MicroRNAs in personalized cancer therapy. Clin Genet. Epub February 14, 2014.

104. Properzi F, Logozzi M, Fais S. Exosomes: the future of biomarkers in medicine. Biomark Med. 2013;7(5):769-778.

105. Schwarzenbach H, Nishida N, Calin GA, Pantel K. Clinical relevance of circulating cell-free microRNAs in cancer. Nat Rev Clin Oncol. 2014;11(3):145-156.

106. Tanaka Y, Kamohara H, Kinoshita K, et al. Clinical impact of serum exosomal microRNA-21 as a clinical biomarker in human esophageal squamous cell carcinoma. Cancer. 2013;119(6):1159-1167.

107. Munoz JL, Bliss SA, Greco SJ, Ramkissoon SH, Ligon KL, Rameshwar P. Delivery of functional anti-miR-9 by mesenchymal stem cell-derived exosomes to glioblastoma multiforme cells conferred chemosensitivity. Mol Ther Nucleic Acids. 2013;2:e126.

108. Katakowski M, Buller B, Zheng X, et al. Exosomes from marrow stromal cells expressing miR-146b inhibit glioma growth. Cancer Lett. 2013;335(1):201-204.

109. Viaud S, Thery C, Ploix S, et al. Dendritic cell-derived exosomes for cancer immunotherapy: what's next? Cancer Res. 2010;70(4): $1281-1285$.

110. Clayton A. Cancer cells use exosomes as tools to manipulate immunity and the microenvironment. Oncoimmunology. 2012;1(1):78-80.

111. Rak J. Extracellular vesicles - biomarkers and effectors of the cellular interactome in cancer. Front Pharmacol. 2013;4:21.

OncoTargets and Therapy

\section{Publish your work in this journal}

OncoTargets and Therapy is an international, peer-reviewed, open access journal focusing on the pathological basis of all cancers, potential targets for therapy and treatment protocols employed to improve the management of cancer patients. The journal also focuses on the impact of management programs and new therapeutic agents and protocols on

Submit your manuscript here: http://www.dovepress.com/oncotargets-and-therapy-journal
112. Alvarez-Erviti L, Seow Y, Yin H, Betts C, Lakhal S, Wood MJ. Delivery of siRNA to the mouse brain by systemic injection of targeted exosomes. Nat Biotechnol. 2011;29(4):341-345.

113. Shtam TA, Kovalev RA, Varfolomeeva EY, Makarov EM, Kil YV, Filatov MV. Exosomes are natural carriers of exogenous siRNA to human cells in vitro. Cell Commun Signal. 2013;11:88.

114. Rana S, Yue S, Stadel D, Zoller M. Toward tailored exosomes: the exosomal tetraspanin web contributes to target cell selection. Int $J$ Biochem Cell Biol. 2012;44(9):1574-1584.

115. Yang L, Wu XH, Wang D, Luo CL, Chen LX. Bladder cancer cellderived exosomes inhibit tumor cell apoptosis and induce cell proliferation in vitro. Mol Med Rep. 2013;8(4):1272-1278.

116. Christianson HC, Svensson KJ, van Kuppevelt TH, Li JP, Belting M. Cancer cell exosomes depend on cell-surface heparan sulfate proteoglycans for their internalization and functional activity. Proc Natl Acad Sci U S A. 2013;110(43):17380-17385.

117. Rodriguez-Boulan E, Kreitzer G, Musch A. Organization of vesicular trafficking in epithelia. Nat Rev Mol Cell Biol. 2005;6(3):233-247.

118. Hsu C, Morohashi Y, Yoshimura S, et al. Regulation of exosome secretion by Rab35 and its GTPase-activating proteins TBC1D10A-C. J Cell Biol. 2010;189(2):223-232.

119. Zhang JX, Huang XX, Cai MB, et al. Overexpression of the secretory small GTPase Rab27B in human breast cancer correlates closely with lymph node metastasis and predicts poor prognosis. J Transl Med. 2012;10:242.

120. Thompson CA, Purushothaman A, Ramani VC, Vlodavsky I, Sanderson RD. Heparanase regulates secretion, composition, and function of tumor cell-derived exosomes. J Biol Chem. 2013; 288(14):10093-10099.

121. Koumangoye RB, Sakwe AM, Goodwin JS, Patel T, Ochieng J. Detachment of breast tumor cells induces rapid secretion of exosomes which subsequently mediate cellular adhesion and spreading. PLoS One. 2011;6(9):e24234.

122. Keller S, Konig AK, Marme F, et al. Systemic presence and tumorgrowth promoting effect of ovarian carcinoma released exosomes. Cancer Lett. 2009;278(1):73-81.

123. Ohno S, Takanashi M, Sudo K, et al. Systemically injected exosomes targeted to EGFR deliver antitumor microRNA to breast cancer cells. Mol Ther. 2013;21(1):185-191.

124. Kosaka N, Takeshita F, Yoshioka Y, et al. Exosomal tumor-suppressive microRNAs as novel cancer therapy: "exocure" is another choice for cancer treatment. Adv Drug Deliv Rev. 2013;65(3):376-382.

125. Umezu T, Ohyashiki K, Kuroda M, Ohyashiki JH. Leukemia cell to endothelial cell communication via exosomal miRNAs. Oncogene. 2013;32(22):2747-2755.

126. Camacho L, Guerrero P, Marchetti D. MicroRNA and protein profiling of brain metastasis competent cell-derived exosomes. PLoS One. 2013;8(9):e73790.

127. Katsuda T, Kosaka N, Takeshita F, Ochiya T. The therapeutic potential of mesenchymal stem cell-derived extracellular vesicles. Proteomics. 2013;13(10-11):1637-1653.

128. Riches A, Campbell E, Borger E, Powis S. Regulation of exosome release from mammary epithelial and breast cancer cells - a new regulatory pathway. Eur J Cancer. 2014;50(5):1025-1034.

\section{Dovepress}

patient perspectives such as quality of life, adherence and satisfaction. The manuscript management system is completely online and includes a very quick and fair peer-review system, which is all easy to use. Visit http://www.dovepress.com/testimonials.php to read real quotes from published authors. 